Path creation by public agencies - the case of desirable futures of genomics

Wouter P.C. Boon ${ }^{\mathrm{a}^{*}}$, Erik Aarden ${ }^{\mathrm{b}}$ and Jacqueline E.W. Broerse ${ }^{\mathrm{c}}$

Please cite as: Boon, W.P.C., Aarden, E., \& Broerse, J.E.W. (2015). Path creation by public agencies-The case of desirable futures of genomics. Technological Forecasting and Social Change, 99, 67-76.

${ }^{a}$ Innovation Studies, Copernicus Institute of Sustainable Development, Utrecht University, Heidelberglaan 2, 3584 CS Utrecht, the Netherlands. E-mail: w.p.c.boon@uu.nl

${ }^{\mathrm{b}}$ Department of Science and Technology Studies, the University of Vienna, Universitätsstraße 7, A-1010 Vienna, Austria. E-mail: erik.aarden@univie.ac.at

${ }^{c}$ Athena Institute, VU Amsterdam, De Boelelaan 1085, 1081 HV Amsterdam, The Netherlands. E-mail: j.e.w.broerse@vu.nl

* Corresponding author:

Wouter P.C. Boon

Innovation Studies, Copernicus Institute of Sustainable Development, Utrecht University, Heidelberglaan 2, 3584 CS Utrecht, the Netherlands. Phone: +31(0)302532708.

w.p.c.boon@uu.nl 


\title{
Path creation by public agencies - the case of desirable futures of genomics
}

\begin{abstract}
Public agencies are central actors in the emergence of technologies. They use their cognitive resources and instruments (regulation, public procurement) to deal with new technologies, against the backdrop of institutional frames and particular responsibilities in serving the 'public good'. How these public agencies anticipate emerging sociotechnical futures has so far remained underexplored. This article aims to explore public agencies' anticipatory role as a 'knowledgeable actor'. A conceptual model is proposed that builds on path creation and mindful deviation literature. This conceptualization is explored for the case of genomics in health care insurance in the Netherlands by making an innovative link between a retrospective study on the integration of genomics in public health insurance with prospective scenarios of possible futures for genomics and insurance. Our findings show that policy agents enter anticipatory exercises in a tentative way, carefully drafting next steps, taking into account current boundaries, positions and historical institutional contexts. Their 'local' approach to emerging technologies can, however, influence 'global' technological and institutional developments. In this context, path creation scenarios can contribute to anticipatory governance that serves societal interests by early-stage identification of moments of potential intervention.
\end{abstract}

\section{Keywords:}

Path creation; emerging technologies; scenarios; public administration; health care insurance; genomics 


\section{Introduction}

A wide range of uncertainties regarding their further development and social effects commonly surrounds emerging and breakthrough technological innovations. Therefore there are apparent reasons for prospecting emerging innovations, e.g. companies might want to prepare for future opportunities and public agencies have a need for anticipation on societal impacts of new technologies. Yet, new technologies always emerge in the context of socioinstitutionally and historically preconfigured selection environments. On the one hand, the variety in development paths of technologies is augmented by changes in this selection environment, which has been recognized in CTA (Robinson, 2009) and transition literature (Geels and Schot, 2007). At the same time, the selection environment restricts variety; possibilities are bounded by historical contingencies, such as the economic environment, technological paradigms and regimes, and institutions. In anticipating and steering the pathways of technological innovation, it is therefore crucial to recognize the implications of historical socio-technical developments. Analytically, this might imply a need for linking retrospective studies of technological development, uncovering the non-linear innovation journeys, with prospective studies. Such prospective perspective should take into account restrictions laid out by historical contingencies but also leave room for flexibility in defining different pathways into the future and in perceiving the selection environment as prone to change.

While literature on anticipating technological change and its social consequences promotes sensitivity to the institutional and historical circumstances that shape innovation journeys, less explicit attention is given to the role of public agencies in shaping innovation pathways. Of course there are public organizations whose dedicated task is to conduct technology assessment. In this article we focus on public agencies that have a role as regulators, 
purchasers and/or users of new technologies in a particular policy domain, such as healthcare. They are often explicitly assigned the task to consider collective interests and social implications of new technologies in terms of the public good, like maintaining quality, affordability and accessibility of medical care, but conducting technology assessments normally falls outside their remit and capabilities.

The socio-technical character of emerging technologies and the large role of public institutions in defining domains of application thus suggest that intervention by these institutions towards the public goals they are supposed to serve should be possible. In this regard, it is assumed that public agencies are central to anticipatory governance of new technologies that have the potential to serve public goals. This paper therefore proposes how public agencies can explore sociotechnical futures, taking developments in incorporating genomics in health care insurance as a case.

Conceptually, we build on path creation literature that suggests that proactive stakeholders should "meaningfully navigate a flow of events even as they constitute them" (Garud and Karnoe, 2001, p. 2). These actors investigate possible ways forward without losing sight of existing structures and boundaries, thereby pursuing 'mindful deviation'. This article aims to add to current literature by studying path creation and mindful deviation (e.g. Djelic and Quack, 2007; Garud and Karnoe, 2001) focusing on public bodies, anticipating the development and consequences of emerging technologies. Most literature on anticipation of future technologies by public agencies has focused on policy making and policy instruments (Borrás and Edquist, 2013) or public agencies participating in wider consultation. Instead we focus on public agencies as central figures in path creation and explore to what extent these actors use their cognitive resources and instruments (regulation, public procurement) to deal 
with new technologies, against the backdrop of institutional frames and particular responsibilities in serving the 'public good'. At the same time, public agencies are not operating in isolation. We therefore also consider the role of public institutions in their wider social and historical context, addressing questions about how historically developed configurations facilitate and restrict actions by public institutions to influence innovation, and how interventions by specific organizations can be scaled up to wider technological regimes. To this end, we conceptualized and operationalized mindful deviation in such a way to include the co-evolution of historical contingencies, the selection environment and technology development as proposed by Robinson (2009), explicitly linking past and future development of technology as recently suggested by Breukers and colleagues (2014).

We explore the role of public institutions in anticipating emerging sociotechnical futures for the case of genomics in health care insurance in the Netherlands. Human genome research is considered to be laying the foundations for the future of medicine. Increasing insight into the structure and functions of human DNA as well as interactions with lifestyle and environmental influences are supposed to contribute to a radically improved understanding of the mechanisms of disease (Malik and Khan, 2010; Nightingale and Martin, 2004; PriceWaterhouseCoopers, 2005; Royal Society, 2005). Among the medical benefits expected to emerge from human genome research are an improved understanding of the course of diseases, the development of predictive and preventive approaches in health care and better tailored development and prescription of drugs (Ashley et al., 2010; Belsky et al., 2013; Khatri et al., 2012). Despite these potential benefits to health care, questions and concerns are still surrounding this kind of research. Part of these concerns relate to the predictive capacities of genetic information and its potential misuse leading to the exclusion of genetically predisposed individuals from various social goods and services (Macdonald, 2003; 
McGleenan et al., 1999; Nelkin and Tancredi, 1994). A pressing question for public organizations developing health care policies is thus how to produce advances in medical technologies that are socially productive and reflect societal underlying values, such as solidarity.

Section two develops a framework for analyzing path creation concentrating on the coevolution of technology and socio-institutional boundaries, taking public agencies and their tasks and desirable socio-technical futures as the focal point of study, at the same time positioning these organizations in a wider environment. This framework is useful for making an explicit case for investigating possibilities for public policy intervention in the emergence of new technologies in future scenarios. The third section elaborates how to identify possibilities for public policy intervention by describing the methodological approaches to the studies of contemporary health care governance and future scenarios. One of these studies investigates the recent integration of genetic technologies in health care in the Netherlands and elsewhere. On the basis of that study, section four describes a number of potential intervention moments where public authorities have influenced the trajectory of emerging genetic technologies into health care. The second study comprises a scenario exercise with policy makers at the Dutch Health Care Insurance Board (College voor Zorgverzekeringen, hereafter CVZ), aimed at identifying likely and desirable futures for genomics in health care. Section five describes these scenarios more fully and maps the moments of intervention onto the scenarios, indicating mindful deviation and opening up room for intervention to promote the interests of widely accessible and affordable health care. In the concluding section, we address the value and limitations of our combined retrospective and prospective approach to study path creation activities by public agencies. 


\section{Theoretical framework}

The emergence of a new technology is perceived as a co-evolution of technological dimensions and socio-institutional embedding (cf. Nelson and Winter, 1982). Following the literature on constructive technology assessment (CTA), the co-evolution of technology and society can be made more reflexive by stimulating deliberative interactions between design, development, implementation and use phases (Rip et al., 1995). Recently, CTA scholars conceptualized the emergence of new technologies as a path that consists of moments marking irreversible courses of development, creating the possibility to steer and modulate technology development in real time (Robinson and Propp, 2008). With this, they aligned with the growing literature on path creation. Path creation connects the notion of path dependence, i.e. the process of small events and differences leading to one technology becoming dominant through increasing returns and network externalities (Arthur, 1990; David, 1985), with distinguishing different possible routes for technology development (Garud and Karnoe, 2001). The process of path creation includes deliberate reflection on possibilities to divert from existing paths. This "mindfulness implies an ability to disembed from existing structures [that define] relevance and also an ability to mobilize a collective despite resistance and inertia that path creation efforts are likely to encounter" (Garud and Karnoe, 2001). Besides the focus on historical embedding and 'mindful deviation', path creation underlines that actions of actors have consequences for the paths that are in the making. In this way, actors influence path creation in a real-time and enterprising manner.

Path creation thus aims to connect past contingencies with future possibilities. To explore this connection and treat these paths as emergent, flexible, distributed but also in need of guideposts, we employ two concepts: moments and visions. In our discussion here, we understand such moments to be the points where societal actors intervene in innovation 
pathways to steer or constrain applications of new technologies in morally-desired directions. Our analysis of such moments is inspired by Jasanoff's concept of '(bio-)constitutional moments' (Jasanoff, 2011, 2003). With this concept, she draws attention to the way technologies and basic categories of social organization are jointly defined and produced. The moments we thus analyze below shape the normative choices public bodies make at various points in the incorporation of technologies in their processes, thereby reconfiguring the pathways of innovation.

The second concept used to forecast the path that technology development and the societal embedding of that technology will take, is by actively shaping visions of the future (Grin and Grunwald, 2000; Roelofsen et al., 2008). Thinking in terms of such desirable socio-technical futures plays a significant role in path creation. Underlying these visions are expectations that, on the one hand, are based on historical legacy in the sense that innovators reflexively engage with future expectations, identifying earlier failures, considering potential barriers for innovation (Tutton, 2011) and renouncing particular visions as unrealistic (Selin, 2007). On the other hand, expectations are also dictating future developments: expectations, once they are part of a shared agenda, become requirements for action in the present (Brown and Michael, 2003; van Lente and Rip, 1998). 


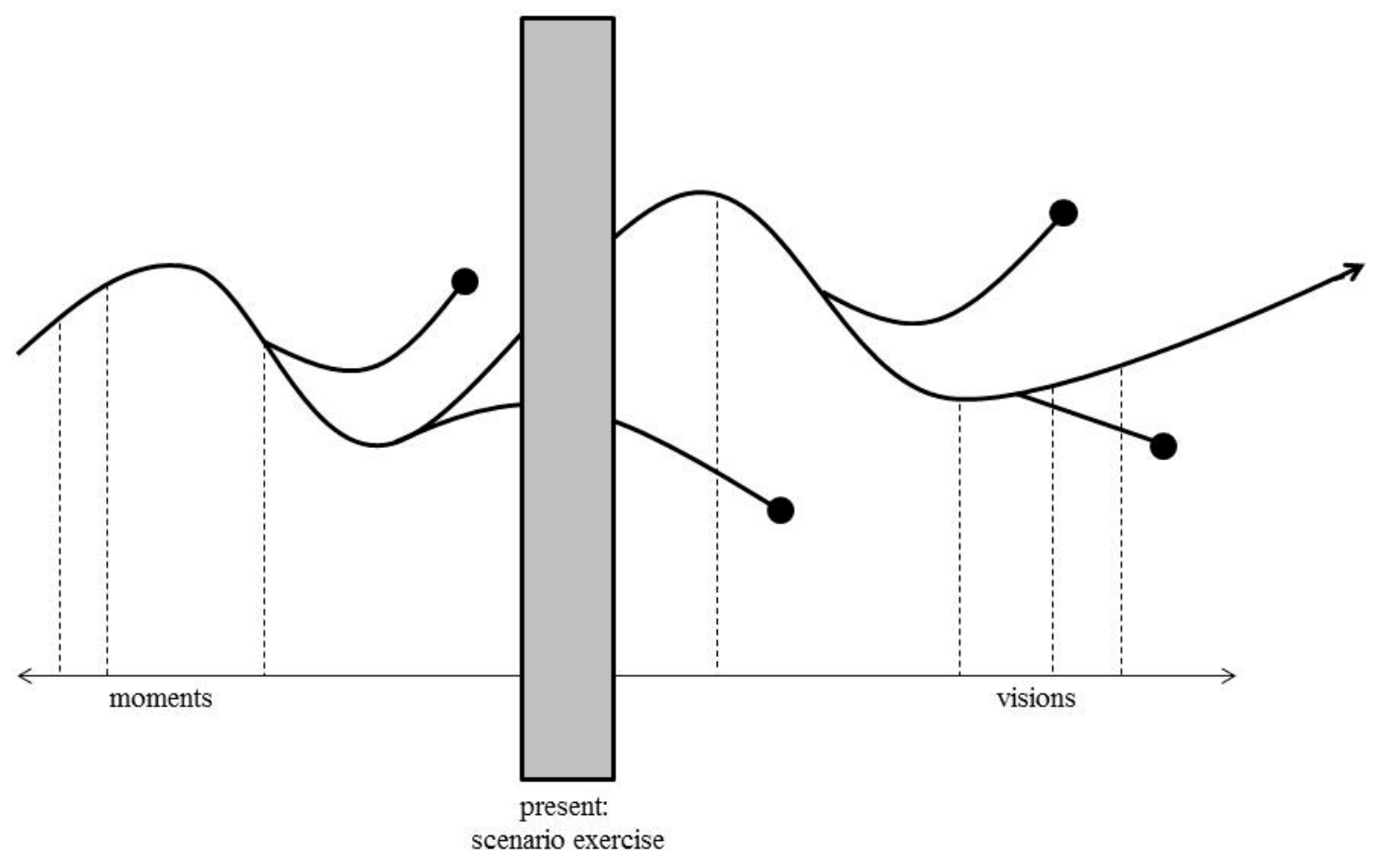

Figure 1: position of moments and visions in creating scenarios of innovation paths.

Figure 1 shows the connection between moments and visions. The history-dependent moments and future-oriented visions articulate implicit or explicit institutions and normative imaginations. Together moments and visions form arrangements that are semi-fluid but because of investments done by relevant stakeholders increasingly become 'obligatory passage points' or 'emerging irreversibilities' (van Merkerk and van Lente, 2005). These points build on implicit or explicit institutions and normative imaginations of where innovation should go and hereby create the future shape of innovation paths.

These moments and visions figure as points of departure for building scenarios about possible futures of an emerging technology, hereby operationalizing mindful deviation through scenario building. Insights into these moments, visions and eventual scenarios help 
stakeholders to become more knowledgeable about future possibilities, hereby being better able to actively engage in path creation. This scenario building should lead to depicting possible "broad-brush pictures" of futures (Wright et al., 2013), taking into account historical contingencies and at the same time leaving room for real-time interventions by actors. Our approach takes the historical, socio-institutional, technological and normative contingencies as starting points, aiming to extend the focus of the scenarios from desirable or preferable futures into showing which different technology paths are possible given these points of departure (Roelofsen et al., 2008). The scenarios are created on the basis of important but uncertain driving forces and different normative assumptions.

From a scenario theory perspective our approach can also be categorized as exploratory and normative (van Notten et al., 2003). The exploratory character follows from taking possible issues as causes and investigating the chain of causality into the future to reveal what might happen (Börjeson et al., 2006; Ducot and Lubben, 1980). In scenarios that uncover possible futures it is common to include normativity, e.g. because scenarios are constructed from certain perspectives (van Notten et al., 2003) or follow ideal-type models of the world. Shell scenarios had initially been drafted to sense changes in the external environment in order to exploit opportunities. However, Shell based its recent 'New Lens scenarios' on broad perspectives of how the world should be organized (Shell, 2014). Such an approach intensifies the interdependency between environment and actor's 'emergent strategies', i.e. "when companies engage in actions that evolve unplanned from past patterns or newly recognized patterns in the business environment” (Bodwell and Chermack, 2010). Normally, the main purpose is to inform decision makers about how to anticipate and make sense of emerging technologies (Barben et al., 2008). However, this intense interdependency - in line with the notion of path creation - calls for more influential scenarios and visions that directly 
intervene in the environment and actor's strategy (O’Connell et al., 2010).

Such interdependence between the environment and single actor's strategies, or how agency's visions and ideas relate to broader institutional frames and general technological development, can be conceptualized on two levels. These levels, borrowed from transition studies (Geels and Raven, 2006), distinguish between the 'local' and the 'global'. These levels do not refer to geographical denominations but point to the level of specificity. Local ideas are tailor-made and context-specific, whereas the global level refers to an abstract and generic set of shared rules, problem agendas, search heuristics, etc. Van Lente and colleagues (2013) also discern expectations on three levels of aggregation (micro-meso-macro). The analytical framework applied here recognizes this interplay between different levels in technology development and explores two different levels of specificity across moments and visions:

- Local level: moments and visions as articulated and framed on the level of, and specific to, the (public) actor.

- Global level: moments and visions that position the technology in a wider more generalized (socio-institutional) frame.

In sum, scenarios of possible futures are created that are based on historical and socioinstitutional contingencies through the use of the concepts 'moments' and 'visions', which serve as emerging irreversibilities. Stakeholders can thus pursue 'mindful deviation' by working on new developments and, at the same time, taking into account existing routines, infrastructures and cultural preferences as well as global socio-institutional frames. Such an approach underlines that path creation is a co-evolutionary and a multi-level exercise. In our exploration of the future of genomics in publicly-financed health care, technology is molded 
by socio-institutional context and vice versa.

\section{Methods}

As was introduced in the previous sections, future technology paths can be regarded as emerging from historical contingencies and guided by future visions. A way to study path creation is to connect a retrospective and a prospective focus and regard these perspectives as interrelated. In analyzing how specific moments in which public authorities (may) intervene in the incorporation of genomic technologies in medicine relate to the realization of visions incorporated in future scenarios, we relate a retrospective with a prospective study of genomics in health insurance in the Netherlands. The retrospective part sought to identify how existing genetic technologies are currently covered within the mechanisms of health care reimbursement in the Dutch insurance system. This study thus traces how reimbursement decisions have been made in the recent past, thereby indicating in which specific localities the constitution of particular distributive approaches for genomics health care took shape and how these developments related to 'global' frames. The second study consists of the development of scenarios aimed at identifying how the 'global' emergence of genomics may relate to the 'local' role of CVZ. CVZ is a public organization that is officially responsible for determining which forms of medical care are covered by the obligatory insurance scheme in the Netherlands. In this section, we outline the methods employed, thereby showing how the retrospective and prospective perspectives were analyzed.

\subsection{Retrospective perspective}

The study of the incorporation of existing genetic technologies in Dutch health insurance was part of a larger comparative assessment of the incorporation of genetics in public health care 
coverage in three European countries. In addition to obligatory health insurance in the Netherlands, this assessment included statutory health insurance in Germany and the National Health Service (NHS) in the United Kingdom. The aim of this broader study was to identify how different locally-specific arrangements for the distribution and reimbursement of medical care have incorporated genetic technologies and developed specific routines for making these technologies available to groups of patients or individuals at risk. The study focuses on the practices of policy makers and clinicians in distributing three areas of application of genetic knowledge and diagnostic techniques: pre-implantation genetic diagnosis (genetic testing and selection of embryos conceived in vitro), risk assessment for hereditary breast cancer predispositions through genetic testing and family history analysis, and genetic testing and family history diagnostics for hereditary high cholesterol (familial hypercholesterolemia).

Data collection and analysis of the incorporation of genetic health care technologies was based on an in-depth qualitative approach, using semi-structured interviews and document analysis. In the Netherlands, documents included health care regulation and policy papers, medical guidelines and published guidance as well as archival materials on distributive decisions made by CVZ. Insights into health care reimbursement practices as discussed in documents were corroborated with interviews with clinical professionals, policy makers and representatives of the insurance industry in the Netherlands, both on the 'local' and the 'global' level. A total number of 16 people were interviewed between late 2004 and May 2009. Of these 16 people, 9 were medical professionals, including both clinicians and researchers in genomics as well as other fields, 6 were public officials at government departments or other public institutions, and 1 was a representative of the health insurance industry. Interviews addressed issues such as the regulation and organization of genetic medical services. For specific technologies they further addressed mechanisms of health care 
distribution, controversies around financing and reimbursement, etc. Within the interview and documentary materials, triangulation between sources provided insight into the specific moments at which further directions of technology development were shaped by the various actors involved.

\subsection{Prospective perspective}

The second part of this article concerns the construction of scenarios about the future influence of genomics on health insurance and related policy options for CVZ. As was introduced in the theory on path creation, scenarios describing future developments are entrenched in past activities, institutional boundaries and trends encountered by CVZ. The scenarios provide a translation of the imagination and expectations for the future as embodied in the knowledge of current actors, in this case the employees of CVZ. In this regard, Van Rijswoud and colleagues (2008) call this “controlled imagination” - stories that describe the future based on current observable activities, developments and decisions. Our foresight exercise builds on this and explicitly adds the perspective of health insurance. We combined consultation, in this case in the form of interviews, focus groups and workshops, with scenario development, which aligns to recent developments in the theory and practice of scenario methodology (Roelofsen et al., 2008; Wright et al., 2013). Figure 2 summarizes the approach. 


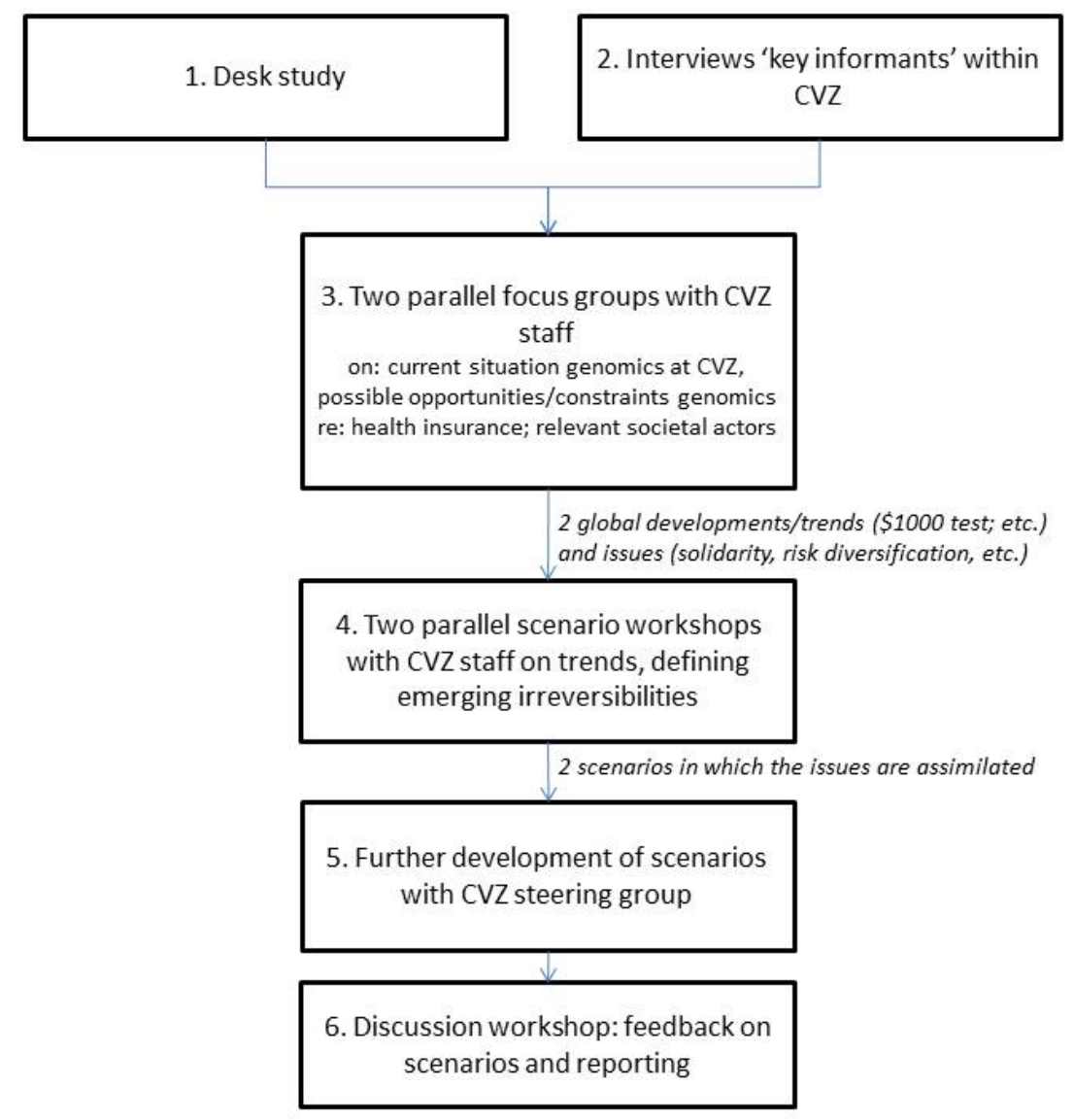

Figure 2: schematic overview of methodology to construct prospective scenarios.

The approach consists of the following steps:

I. $\quad$ Desk research and start meeting

The trajectory started with an information meeting in which the state-of-the-art of genomics and genetics science was presented to and discussed with the participating CVZ personnel.

\section{Interviews with 'key informants'}

In this step the researchers conducted five in-depth interviews with higher-echelon CVZ policymakers to clarify important issues and provide input for the interactive sessions, e.g. in the form of visions.

\section{Focus groups: bottlenecks and opportunities}

In two parallel focus groups, each consisting of seven participants, information is exchanged on various topics related to genomics and health insurance. To prepare for these focus groups, 
the participants had received a chapter of a report on current genomics science. During the focus groups the moderators partially steered the direction of the discussions by asking questions, giving opinions and articulating doubts. The task of the moderator was to stimulate mutual investigation and to make sure that the discussion remained substantive and constructive. The discussions focused on the following topics: 1) scientific trends in genomics for the short- and medium-term future; 2) how CVZ had dealt with genomics until then ('local level'); 3) assessing the impact of the scientific trends on insurance-related bottlenecks and opportunities for CVZ ('influence of global level’); 4) assessing which external parties could exert pressure on CVZ as result of genomics-related insurance issues, and the nature of this pressure ('influence of global level’).

\section{Scenario workshop}

The follow-up meeting was in the form of two parallel scenario workshops consisting of six and seven persons, most of whom had participated in the focus groups. The objective of these workshops was to produce a rich set of scenarios of the near future of health insurance and the related role of CVZ vis-à-vis developments in genomics. Based on the results of the previous steps, i.e. focus groups, desk research and interviews, the following two visions of 'global' developments were formulated as input for the workshop:

- Increased pressure on the basic package of insured care as a result of growing individual genetic screening and the advent of the \$1000-genome test.

- Increase of 'personalized medicine'.

These visions were enriched and elaborated in a structured way during the meetings. This structure was provided by returning to the same issues, which had been raised during the focus groups, such as legal criteria and definitions, solidarity and ethical aspects. The participants of the scenario workshop were asked to discuss and conceptualize the foreseeable future, using the abovementioned issues, and thus defining upcoming critical decisions 
moments, i.e. emerging irreversibilities. To introduce the time element in the scenarios, we chose to subdivide the scenarios into periods of three to four years (2010-2013, 2014-2016, 2017-2020). The baseline period (2007-2009) had already been dealt with in the focus groups.

\section{Elaboration of scenarios}

Based on the results of the focus groups and scenario workshops, the researchers finalized the scenarios. The resulting two scenarios were: (1) increase in commercial offerings of individual genetic screening and (2) increase in 'personalized medicine'. The characteristics of the scenarios for health insurance can be described as complementary stories about possible developments, issues and dilemmas, as such defining emerging irreversibilities. The distinction between global and local developments is also articulated in the scenarios.

\section{VI. $\quad$ Discussion meeting: feedback on scenarios and reporting}

The scenarios were presented to the interview partners and participants of the focus groups, scenario workshops and other invitees during a closing discussion meeting. The draft report served as input for this meeting. In the final report the feedback of the final meeting was taken into account.

\section{Retrospective perspective: Incorporating genomics in Dutch health care distribution}

This section provides a retrospective analysis of the 'moments' where public institutions intervened to shape the application of genetic technologies in health care in the Netherlands moments that were both shaped by existing visions of how to incorporate genetics in health care, and continued to shape subsequent visions (Brown and Michael, 2003). It describes the co-evolution of genetic technologies with medical practice and health care delivery, in the particular institutional framework of Dutch health care. Health care in the Netherlands is 
financed through population-wide insurance coverage. What basic insurance covers exactly is defined by the Ministry of Health, which also regulates the permissibility of particular procedures. However, a central institution that our analysis focuses on is CVZ, which is the main organization responsible for defining which specific medical interventions are reimbursed through basic health insurance. Considering the costs of medical technologies and the deeply held belief that health care should be collectively financed, this organization in effect determines when and how medical technologies can be used in medicine in the Netherlands. While its decisions often concern specific technologies (i.e. the 'local' level), they often have ramification for other, similar forms of care (the 'global' level).

This section discusses three different forms of interventions actors in the Dutch health care system, and CVZ in particular, have taken at particular moments towards the managed integration of genetics in medicine: regulation, institutionalization and classification. While these examples are not exhaustive for the manifold ways the constitution of genomics-based health care in Dutch insurance can take place, it covers some of the most salient moments and indicates what the salient instances in the further path creation of genomic technologies and health insurance in the Netherlands may be.

\subsection{Regulation}

From the advent of genetics in the 1970s onwards, diagnosing the contribution of hereditary factors to disease has had a highly circumscribed legal status in the Netherlands. Genetics is legally restricted to university hospitals, where until recently genetics clinics were established as financially separate 'foundations' under the umbrella of university hospitals. There have been several motivations for establishing genetics in this particular way. One of the reasons was to balance control of a new, highly specialized, experimental and controversial field with 
an opportunity for the field to flourish and develop.

CVZ played a large role in the definition of boundaries of genetics in health care. Even though it is not a regulatory institution, CVZ was involved in establishing contracts between the insurance industry and genetics clinics on how to finance genetic medicine. This shows how regulation has served the purpose of balancing the establishment of a new field with securing both ethically and financially 'appropriate use' of resources, thereby setting the boundaries for how the field of genetics was supposed to operate. Limiting genetic testing to these distinct places invited 'local' solutions to be developed. The existence of separate foundations is often said to have influenced the development of new diagnostic technologies in the Netherlands, in particular the establishment of sequencing techniques that are of interest in the context of more ‘common’ diseases (Nelis, 1998).

A specific example where regulation, or actual lack thereof, has shaped the boundaries of adequate applications of genetic technologies in health care can be found in the emergence and resolution of a brief controversy over pre-implantation genetic diagnosis (PGD) in 2008. As a highly experimental and controversial procedure that involves genetic testing of IVF embryos and selection of embryos free of inherited diseases and disabilities, PGD has been subject to additional regulation since its earliest clinical applications in the Netherlands. Under the decree as described above that restricts clinical genetics to university hospitals, PGD is limited to one particular university hospital in Maastricht, although availability of the procedure has broadened in recent years due to the establishment of 'satellite' clinics elsewhere. Initially, regulation of PGD did not indicate for which diseases the procedure was considered to be applicable, and decisions on specific applications were made at the one PGD clinic. According to one person involved in the PGD clinic, this was both to avoid 
'blacklisting' particular conditions as sufficiently serious to warrant prevention and to circumvent discussions about the various degrees of severity of genetic conditions in individual patients. However, in 2008 the deputy minister of health proposed more stringent criteria for PGD, which resulted in wide public outrage centered on the possible ban of PGD for mutations predisposing for breast cancer. This public outrage forced the deputy minister to reconsider which limitations to the application of PGD would be acceptable to Dutch public opinion. Eventually, regulatory criteria were reformulated, adding another layer of control in the form of a national committee reviewing potential applications of PGD and broadly describing the technology as applicable to 'an increased risk for a serious condition'. In addition to these criteria, the application of PGD is determined by CVZ criteria which limit reimbursement of medical procedures to applications that are common in an international context. This criterion potentially further restricts the list of diseases PGD can be applied to. In this 'moment' the way in which the technology was supposed to work and applied became (re-)articulated.

\subsection{Institutionalization}

Through the institutionalization of specific medical pathways, organizational dimensions of health care further contribute to determining under which circumstances genetic diagnostics should be reimbursed in health insurance. This is shown in the example of breast cancer predispositions. For women who are concerned that a higher chance of developing breast cancer exists in their family, geneticists in the Netherlands use diagnostic criteria developed by an organization that collects data on and prepares guidelines for diagnosing hereditary cancer risks. Diagnostic guidelines are based on women's lifetime risk of developing breast cancer, which is calculated on the basis of the age at which cancer was diagnosed in two firstdegree relatives. Guidelines further describe criteria for follow-up for various risk groups and 
propose to perform genetic testing for the category of high-risk women only. However, several clinicians had experienced that in many cases the advice to regularly monitor women with an increased breast cancer risk is not adhered to. For this reason, cancer geneticists in the Netherlands decided to take follow-up of women found to have a genetic mutation in their own hands. They have established integrated outpatient clinics for hereditary tumors, where women receive coordinated appointments with geneticists, surgeons and radiologists who provide monitoring. In terms of normative choices in innovation pathways, the establishment of this technological solution forms a 'moment' where a particular subset of women at risk (those with a molecular diagnosis) are positioned as being more legitimately at risk than others. Consequently, these women have better access to health care reimbursed by insurance companies. Moreover, this particular, 'local' arrangement has drawn interest in other areas where hereditary risks for common disorders are at the center of attention, thus becoming a more 'global' phenomenon. Such institutionalization is actively facilitated by CVZ, which supports the financial foundations of these initiatives.

Another way in which CVZ supported molecular genetic initiatives was to institutionalize circumscribed spaces in which actors can develop new solutions protected from external pressures. One prominent example is a patient organization and a physician managed setting up a screening program for familial hypercholesterolemia (FH), a hereditary predisposition to high cholesterol. This screening program is run by a foundation that was established with the purpose of operating FH screening. To efficiently organize this program, genetic testing is limited to two genes, the LDL-receptor gene and the Apoliprotein B-gene, which are strongly correlated with increased cholesterol levels. Testing of these genes has been highly standardized and automated and is largely done in a special laboratory that one administrator described as almost industrial in character. This approach explicitly excludes other, more 
complex, hereditary forms of high cholesterol from extensive medical attention. The decision to establish a screening program with a particular diagnostic focus thus indicates which kind of public health approach to genomics is considered desirable in the Netherlands. This has significance far beyond the 'local' specific condition of FH, since CVZ's program for developing new medical approaches in protective spaces is explicitly aimed at experimenting in new fields and the FH screening program has widely been framed as a pilot for similar programs for other conditions, i.e. on a more 'global' level.

\subsection{Classification}

Through classifications, health care actors aim to distinguish between various categories of disease/risk and link particular courses of action to these categories. In the context of health insurance, classifications serve to distinguish between claims for reimbursement that are considered legitimate and those that are not (Prior, 2001). The classification of breast cancer risks mentioned in section 4.2 reveals notable choices and distinctions made in the integration of genetic technologies in health care coverage. At first sight, the classification of breast cancer risks into three distinctive categories based on women's lifetime chance of developing cancer is clinically motivated. The risk categories provide more insight into how serious individual risks are, and are linked to recommendations as to what appropriate courses of follow-up would be. However, the linkage between risk categories and follow-up services also points to a financial motivation. By prescribing particular forms of follow-up to the various categories of women at risk, classification creates a landscape in which the legitimate allocation of resources is diversified. High-risk women can receive a genetic test and monitoring examinations with greater regularity than women in the moderate risk category. Moreover, women in the low risk category do not get access to additional services, since they are supposed to have a risk that is not significantly increased compared to the general 
(female) population. The creation of a classification scheme for hereditary disease risks is thus another 'moment' where decisions on the desirable application of genomics in medicine are made. In this case, that moment consists of the prescription of particular forms of followup care on the basis of statistically differentiated risks, which in turn shapes the availability and further development of particular screening techniques (e.g. X-ray rather than mammography screening). Such 'local' considerations of how to create risk categories and distribute funding among them can further inspire more general, 'global' ways of further integration of genomics in health insurance by CVZ.

\subsection{Concluding remarks}

This retrospect on 'moments' that shaped the inclusion of genomic technologies in Dutch health insurance shows how various kinds of public intervention can shape innovation pathways. These examples show how a desirable domain of application for genomics in health care is imagined in the Netherlands (Aarden et al., 2010). A central actor in shaping this particular approach to genomics has been CVZ, which shaped the direction of technology development at various 'moments'. From the emergence of genetics onwards, CVZ actively shaped the medical application of genetics - and the technologies - through regulation, institutionalization and classification. For example, regulation mandating only university hospitals to carry out molecular diagnostics has led to particular, often very local technological solutions.

This retrospective discussion thereby has several implications for constructing visions of possible and desirable futures around technological innovation. We saw how various forms of intervention may contribute to steering innovation pathways into a direction that institutions like CVZ may consider to be in the public interest. In addition, we saw how the complexities 
of the relation between interventions aimed at specific technologies or issues ('local level') and more general considerations of futures for genomics in health care ('global level') played out in retrospect. This has implications for scenario building; not only can very specific actions have much more general implications, but the choreographies of specific and general interventions can also inform reflections on how to move forward in a particular innovation domain.

\section{Prospective perspective: Scenarios of socio-technical interaction in genetic}

\section{medicine}

Taking the historical developments and related moments as a starting point, prospective scenarios are created that provide insights into the mindful deviation involved in devising scenarios that mark emerging, desirable innovation pathways. Two of such scenarios are presented below.

\subsection{Scenario 1: Increase in commercially available individual genetic screening}

This scenario builds on the vision that the availability of commercial genetic tests through the Internet gains momentum and that '1000 dollar genome test' becomes available. This significant growth of available commercial tests, or what some actors call a 'sprawl' of tests, involves the rise of technological possibilities and the identification of genes that have a low predictive value in disease risks, leading to more individual screening taking place without direct medical need. The test results merely provide findings in the form of chances, which ends up in anxious consumers seeking interpretation and additional diagnostics by visiting their physician. The commercial tests fall outside regular health care and reimbursement schemes. However, CVZ presumes that these 'global' developments produce an increase in 
demand for primary care, with possibly referrals to secondary care, meaning an increase in health care costs.

CVZ acknowledges that these expectations need to be addressed, especially since they run against CVZ being a co-developer of a history of molecular diagnostics that are confined in designated university hospitals. At this 'moment' in the pathway the CVZ scenario workshop participants assume that waiting is not an option because unbridled growth might continue. It advises the Ministry of Health to build an assessment framework that assists in judging these tests. Such an advise builds on a vision in which CVZ's role is still deemed essential in reimbursement decisions and even in how tests are used. In this scenario, therefore, CVZ begins designing an assessment framework, taking into account 'local' demands including the sufficient level of evidence (e.g. on sensitivity and specificity) and how to make sure that this evidence is provided by the test producers. CVZ decides to draft a Diagnostic Compass, i.e. a handbook that guides consumers and medical professionals on the quality of genetic tests. This institutionalization of diagnostic routes even has a directing function in advising which test to use for certain situations. By controlling levels of evidence, until then delegated to the designated university departments, and use practices the role of clinicians becomes less important (cf. section 4.2). The steering character of the Diagnostic Compass and the requirements that the assessment framework imposes on genetic tests can even lead genetic test producers (who act on the 'global' level) to change the technological design of their tests, e.g. in terms of increasing sensitivity levels.

Next to this development, the global race of producing the first '1000 dollar genome test' yields a winner. Such a test is associated with expectations of completing genetic sequencing of individuals at low costs, which opens possibilities for individual prevention. The imminent 
introduction leads to similar questions about the local implementation and regulation of these tests, indicating another moment in the innovation path of genetic tests. CVZ has several regulatory options, such as signaling that the '1000 dollar genome test' should not be part of the basic package of insured care and should be left to commercial test developers and private health insurance companies. Or that the test should be part of the newborn heel prick screening and as such not part of CVZ's remit. Finally, CVZ can advise to include the test in the basic package, which makes the test subject to the inclusion criteria that CVZ supervises, such as necessity, effectiveness, cost-effectiveness and feasibility. This means that CVZ becomes responsible for complex issues like privacy (chance of abuse, discrimination), access (informed consent), data storage, and data analysis, which has repercussions for the technical set-up of the test. Furthermore, there is the question of responsibility for and financing of the regular re-analysis of data that is needed to test for new scientific insights on associations between genetic mutations and disease susceptibility. Again, these issues might, once taken on board, be used to change the technical implementation (how to automate the re-analysis?) and socio-institutional embedding of the ' 1000 dollar genome test'. The CVZ participants in the scenario workshops had most faith in the option that the test is included in the newborn screening program. This resonates with the institutionalization dynamics as reported in section 4.2, compartmentalizing the genetic testing in a separate scheme.

\subsection{Scenario 2: Increase in 'personalized medicine'}

To strive after optimal treatment, tailor-made or personalized medicine is increasingly mentioned as a way to organize health care. Personalized medicine then functions as a 'global' vision for technology developers, such as pharmaceutical companies. It means that treatment intervenes in genetic and molecular processes that cause the development of diseases. So far, scientific and technological developments have not led to large-scale 
preventive, diagnostic or therapeutic applications. Still, precursors of these developments are already available, including pharmacogenetic medicines and diagnostic tests that assess treatment efficacy.

One of these pharmacogenetic test had caused a stir within CVZ just before the workshops were held. This test that could predict the efficacy of breast cancer therapy had been developed by a Dutch company that was supported by the Dutch government. When the test was introduced on the market CVZ needed to make a "painful" decision to not reimburse it because of a lack of data on whether the test could be safely and efficaciously implemented in the Dutch health care sector.

Therefore, during the scenario workshop CVZ representatives articulated a vision that calls for greater flexibility in reimbursing innovative therapies that are promising but for which evidence is still not sufficient. The tailor-made character of pharmacogenetics products and the fact that diagnostics producers do not have sufficient resources evidence gathering is often hampered. This is made even more difficult because reimbursement decisions are nationspecific, the rationale being that because of distinct health care settings criteria like safety and efficacy work out differently. This means that CVZ assesses new products on a 'local' level and already led diagnostic test producers to gear the setup of their devices to the 'local' contingencies, the aforementioned genetic test being a prominent example.

To make the vision of flexible reimbursement decisions work, CVZ should device a way in which they can regulate new products based on lower datasets. Additional (cost)effectiveness and safety can only be collected when these tests are often used. This leads to a 'chicken-oregg' dilemma since doctors rather use these innovative tests when enough evidence is 
available. To create a way out of this ‘chicken-or-egg' dilemma, CVZ advises the Ministry of Health to introduce a conditional reimbursement scheme for innovative medical technologies. In effect, this institutionalization resembles the protective spaces as introduced in section 4.2, in which through guaranteed reimbursement the genetic test gets the opportunity to be further developed and used. This 'local' space needs to be organized and the ministry asks CVZ to elaborate on how this scheme should work. The question for CVZ is, then, which criteria it needs to apply. To create such a protective space, CVZ cannot stick with 'hard' evidence, demanding rigorous safety and efficacy data. It must accept lower levels of data quality and permit - under certain conditions - an innovation to be part of insured care.

To organize such a protective space, CVZ needs to work on a more detailed proposal in which it is 'milder at the entrance and stricter at the exit'. That is, reimbursement is possible under the condition that the producer collects and reports additional data through post-marketing research. These studies then serve as input for re-evaluation after a period of four or five years. In practice this might lead to changes in indication areas (cf. classification in section 4.3) or the need for changes in the technical set-up, e.g. by introducing combinational diagnostic devices. CVZ compiles a proposal on conditional reimbursement that is favorably received by the Ministry of Health. The scheme is gradually introduced, first applying it to certain test cases and later, after evaluating these cases, on a broader scale. This large-scale, CVZ-centered solution is in contrast with the more bottom-up schemes that were introduced in the regulation and institutionalization episodes (sections 4.1 and 4.2) on PGD testing and testing for breast cancer predisposition, but aligns with top-down classification episode (section 4.3). 


\subsection{Concluding remarks}

As we have seen in the description of the scenarios above, CVZ has certain visions and related expectations about future scientific, technological developments and their own role in the health care sector. These developments are marked on a future timeline. The participants of the workshop and expert group subsequently tried to identify moments on this timeline on which intervention and/or steering was deemed possible or desirable, e.g. because these moments highlight points-of-no-return or irreversible forks in paths. Examples include making choices about the application of decision criteria and demarcating what CVZ should and should not regulate. In some cases, these moments also convey instants on which CVZ itself is able to actively influence technology development or socio-institutional embedding of the genetic technologies. In other words, the global genomics developments are translated to a local context by CVZ and local solutions might, in turn, influence the global level, which e.g. has happened in the past with the pharmacogenetic tests. By this, the scenarios signal future moments on which CVZ needs to take important and irreversible decisions. CVZ can use the scenarios to anticipate on these moments and to proactively articulate visions that might in itself preempt and create the future developments in the pathway regarding genomics in health care.

\section{Discussion and conclusions}

Path creation literature envisages co-evolution between technology and society based on a careful tinkering of technological and societal characteristics rather than 'chance events'. These incremental steps or mindful deviation build on existing technological paradigms, economic and social institutions, and so on. In other words, deviation departs from existing technological paths and selection environments. This article contributes to current 
technological forecasting literature by 1) focusing on public agents (Aarden, 2010), and 2) conceptualizing mindful deviation as a way to bridge the gap between unfolding innovation journeys and the existing selection environment (Robinson, 2009). The aim is, thus, to study how public bodies deal with emerging technologies, taking into account past contingencies and tentatively exploring and creating future paths through mindful deviation. We propose that it is possible for public agents to influence innovation pathways at various points or 'moments' in the trajectory through which an emerging technology is introduced in health care. More specifically, we juxtapose past moments on which such intervention happened with visions of the future, which proactively identifies points in the future on which salient and irreversible decisions need to be taken. Linking retrospective and prospective perspectives on the emergence of genomics and the repercussions for health care insurance as a case study yielded four insights about the piecemeal way public bodies address their concern for the public good in shaping innovation pathways.

First, when conceiving future paths the public policymakers heavily drew on historical contingencies. They explicitly used some of the interventions in the innovation pathways that we found in our retrospective reconstruction of how genetics entered Dutch health insurance. In fact, we found policymakers appreciating these approaches, such as regulation or the creation of particular institutional spaces for nurturing new technical applications. Employing these institutional spaces had repercussions for the future course of technology development as well (Boon et al, 2014). In return for the protection provided by these spaces, CVZ demanded the production of evidence about efficacy. In earlier instances this had led test producers to significantly change the design of and technical infrastructure around genetic test devices. The technological and socio-institutional changes run parallel to other developments in an innovation pathway and are embedded in history. The alignment of the prospective and 
retrospective views shows this path dependency to health care policy making. In other words, future paths are drafted following moments that are based in history, indicating path dependency (Van de Ven, 1992), yet are also emergent and flexible (Garud et al, 2010).

Second, the results show that public bodies are constantly positioning their roles and objectives in a socio-institutional context. The question for health care policy makers to act for or against the reimbursement of particular medical procedures is always simultaneously a question about the boundaries of public responsibility. The particular ways in which these boundary questions have been addressed in the Netherlands continue to inform the scenarios. As a specific example, we demonstrated how Dutch policy makers have taken measures to balance broad coverage with making services available to smaller subgroups. This was, for example, the case for breast cancer mutation carriers, for whom monitoring services were institutionalized in a way tailored to this subgroup. This approach is specific and experimental, and returns in one of the scenarios to implement a conditional reimbursement scheme for innovative medical technologies (cf. Boon et al, 2015). Thus, the normative boundaries of public health insurance get redrawn in both the integration of technologies and the development of future scenarios. These boundary questions are related to the issue concerning which actor is in the driver's seat and to what extent public bodies need to take an (pro)active or reactive stance towards emerging technologies (Van Lente, 2003).

Third, the linkage between retrospective and prospective studies shows that when drafting future paths, representatives of a public body aim for incremental steps. This attitude can be perceived as conscious conservatism. It relates to the two previous points, i.e. the degree of path dependency and of active/passive action, but it also resonates with literature on path dependence and path creation in which actors tend to repeat and replicate successful patterns 
(Garud and Karnoe, 2001; Teece et al., 1997). Another related explanation concerns the fact that mindful deviation demands knowledgeable agents and thus sufficient cognitive resources. Public agents must be able to absorb technological and socio-institutional developments (Cohen and Levinthal, 1990).

We found continuity in the concerns at the heart of both the integration of genomics in health insurance in the past and the imagination of scenarios for future health care insurance. The combination of a retrospective study with future scenarios for the integration of genomics in public health insurance thus shows how policymakers in the Netherlands explore specific policy options to steer technology development (e.g. through demanding certain quality features) and socio-institutional embedding (e.g. through regulation or classification) in desirable directions. Despite ongoing transformations, there is a considerable degree of continuity in the forms of intervention, even though some of the moments and forms of intervention we identified retrospectively are not explicitly considered as such in forwardlooking exercises, such as specific classification issues. Integrating past experiences in future scenarios could thus be a worthwhile option to explore in order to expand the range of policy options under consideration.

Fourth, despite these continuities in normative considerations and despite making technological development endogenous to the scenarios, we see a less-developed sense of the socio-technical character of innovation pathways in the scenarios drawn up by public policy makers. In the scenarios, technical progress is largely represented as a 'global' and autonomous process that poses a set of challenges to policy makers. There, they deal with these challenges through 'signaling', which seems to be an important method to use in cases where policymakers do not have a way of intervening directly, but may be a prelude to more 
directive forms of intervention. In our reconstruction of the incorporation of genetic technologies in Dutch health care, however, we saw how the domain of application for new technologies is shaped by financial and distributive considerations. Concerning the successful implementation of genomics we showed that these public agency demands lead to smallscale, 'local' tailoring, in terms of societal embedding and the design of devices and related infrastructure. These changes might appear to be small-scale and local but these demands might be very compelling, in the sense that public agencies like CVZ are launching customers and through public procurement decide on the adoption of these technologies (Edler and Georghiou, 2007). Moreover, it is precisely these incremental demands for technological change that produce future steps in 'global' technological paths.

These four insights about mindful deviation by public bodies show the methodological possibilities of linking a retrospective and a prospective study into a path creation exercise. There are some limitations to the exercise performed here, which primarily emerge from our attempt to combine two different studies that have some asymmetries in their leading questions and methodological and empirical set-up. Ideally, future research attempts to go one step further and aims to combine the retrospective and prospective parts in such a way that results of the former are directly applied in the latter. Nonetheless, the combination shows the value of merging analyses of innovation pathways on a timeline ranging from the past, through the present, into the future. Additionally, we have limited our scenarios here to one policymaking body that is central to Dutch health care, but has its own circumscribed set of discretions and responsibilities. Our aim was to explore path creation exercises in-depth in one such a body and not to generalize to the total population. Nevertheless, it would be interesting to continue this exercise by contrasting with different types of public bodies that approach new technologies differently or by bringing together a more diverse set of actors to 
create more broadly construed scenarios. Moreover, repeating this approach over a longer time period might provide answers as to what extent public demand articulation influences the course of genomics science and technology.

The creation of scenarios that identify expectations and hopes for new technologies at an early stage can contribute to anticipatory governance (Barben, et al., 2008) that serves societal interests by identifying moments of potential intervention in advance. The combined methodology of retrospective and prospective analysis sheds light on past contingencies through defining 'moments' as well as anticipates on salient moments in the future that public agencies can - and must - anticipate on. As these points lie in the future they are in principle still fluid. At the same time, they are semi-defined and intermediate already since they are influenced by the historical moments as well as future visions and expectations. Moreover, there are vested interests in the definition of these defining moments: actors have already invested in certain outcomes and they have the potential to become irreversible. These emerging irreversibilities or obligatory passage points cannot be ignored when prospecting the future. This makes demands on public agencies; they are well positioned to be involved, because they play a role in steering technological development, e.g. through regulation, reimbursement and public procurement. On the other hand, mindful deviation requires sufficient cognitive resources to act as a 'knowledgeable actor' and it calls for careful deliberation about the level (global versus local) on which action can be decisive. If these challenges are taken into account, we think that scenarios for emerging technologies, informed by past experiences, create opportunities for responsible incorporation of new technologies in a sector of public importance. 


\section{Acknowledgements}

The authors want to thank all participants of the workshops and interviews. We are also grateful to the reviewers and $[\mathrm{x}]$ for their valuable comments.

\section{References}

Aarden, E., 2010. Politics of Provision. The Co-production of Genetic Technologies and Health Care Arrangements in Germany, the Netherlands and the United Kingdom. Maastricht University, Maastricht.

Aarden, E., Van Hoyweghen, I., Horstman, K., 2010. Solidarity in practices of provision: distributing access to genetic technologies in health care in Germany, the Netherlands and the United Kingdom. New Genet. Soc. 29, 369-388.

Arthur, W.B., 1990. Positive feedbacks in the economy. Sci. Am. 80-85.

Ashley, E.A., Butte, A.J., Wheeler, M.T., Chen, R., Klein, T.E., Dewey, F.E., Dudley, J.T., Ormond, K.E., Pavlovic, A., Morgan, A.A., Pushkarev, D., Neff, N.F., Hudgins, L., Gong, L., Hodges, L.M., Berlin, D.S., Thorn, C.F., Sangkuhl, K., Hebert, J.M., Woon, M., Sagreiya, H., Whaley, R., Knowles, J.W., Chou, M.F., Thakuria, J. V, Rosenbaum, A.M., Zaranek, A.W., Church, G.M., Greely, H.T., Quake, S.R., Altman, R.B., 2010. Clinical assessment incorporating a personal genome. Lancet 375, 1525-35.

Barben, D., Fisher, E., Selin, C. (2008) Anticipatory Governance of Nanotechnology: Foresight, Engagement, and Integration, in: Edward J. Hackett, Olga Amsterdamska, Michael E. Lynch, J.W. (Ed.), Handbook of Science and Technology Studies. MIT Press, Cambridge, Mass., pp. 979-1000.

Belsky, D.W., Moffitt, T.E., Caspi, A., 2013. Genetics in population health science: strategies and opportunities. Am. J. Public Health 103 Suppl , S73-83.

Bodwell, W., Chermack, T.J., 2010. Organizational ambidexterity: Integrating deliberate and emergent strategy with scenario planning. Technol. Forecast. Soc. Change 77, 193-202.

Boon, W.P.C., Martins, L., \& Koopmanschap, M. (2014). Governance of conditional reimbursement practices in the Netherlands. Health Policy 119, 180-185.

Boon, W.P.C., Moors, E.H.M., Meijer, A.J. (2014) Exploring dynamics and strategies of niche protection. Research Policy 43, 792-803.

Börjeson, L., Höjer, M., Dreborg, K.-H., Ekvall, T., Finnveden, G., 2006. Scenario types and techniques: Towards a user’s guide. Futures 38, 723-739. 
Borrás, S., Edquist, C., 2013. The choice of innovation policy instruments. Technol. Forecast. Soc. Change 80, 1513-1522.

Breukers, S., Hisschemöller, M., Cuppen, E., Suurs, R., 2014. Analysing the past and exploring the future of sustainable biomass. Participatory stakeholder dialogue and technological innovation systems research. Technol. Forecast. Soc. Change 81, 227-235.

Brown, N., Michael, M., 2003. A Sociology of Expectations: Retrospecting Prospects and Prospecting Retrospects. Technol. Anal. Strateg. Manag. 15, 3-18.

Cohen, W.M., Levinthal, D.A., 1990. Absorptive Capacity: A New Perspective on Learning and Innovation. Adm. Sci. Q. 35, 128-152.

David, P.A., 1985. Clio and the economics of QWERTY. Am. Econ. Rev. 75, 332-337.

Djelic, M.-L., Quack, S., 2007. Overcoming path dependency: path generation in open systems. Theory Soc. 36, 161-186.

Ducot, G., Lubben, G.J., 1980. A typology for scenarios. Futures 12, 51-57.

Edler, J., Georghiou, L., 2007. Public procurement and innovation-Resurrecting the demand side. Res. Policy 36, 949-963.

Garud, R., Karnoe, P., 2001. Path dependence and creation. Earlbaum Associates, Lawrence.

Garud, R., Kumaraswamy, A., \& Karnøe, P. (2010). Path Dependence or Path Creation? Journal of Management Studies, 47(4), 760-774. doi:10.1111/j.1467-6486.2009.00914.x

Geels, F., Raven, R.O.B., 2006. Non-linearity and Expectations in Niche-Development Trajectories : Ups and Downs in Dutch Biogas Development ( 1973 - 2003 ) 18, 375392.

Geels, F.W., Schot, J., 2007. Typology of sociotechnical transition pathways. Res. Policy 36, 399-417.

Grin, J., Grunwald, A., 2000. Vision Assessment: Shaping Technology in 21st century society. Towards a repertoire for Technology Assessment. Springer Verlag, Berlin.

Jasanoff, S., 2003. In a Constitutional Moment: Science and Social Order at the Millenium, in: Nowotny, B.J.\& H. (Ed.), Social Studies of Science and Technology: Looking Back, Ahead. Kluwer, Dordrecht, pp. 155-180.

Jasanoff, S., 2011. Introduction: Rewriting Life, Reframing Rights, in: Reframing Rights. Bioconstitutionalism in the Genetic Age. The MIT Press, Cambridge, pp. 1-27.

Khatri, P., Sirota, M., Butte, A.J., 2012. Ten years of pathway analysis: current approaches and outstanding challenges. PLoS Comput. Biol. 8, e1002375.

Macdonald, A., 2003. Genetics and Insurance: What have we Learned So Far? Scand. Actuar. J. 2003, 324-348.

Malik, N.N., Khan, Y., 2010. Personalized medicine: potential impact on the biopharmaceutical industry. Drug Discov. Today.

Mc Gleenan, T., Wiesing, U., \& Ewald, F., 1999. Genetics and Insurance. BIOS, Oxford.

Nelis, A. (1998). DNA-diagnostiek in Nederland: een regime-analyse van de ontwikkeling van de klinische genetica en DNA-diagnostische tests, 1970-1997. Enschede: Twente University Press.

Nelkin, D., Tancredi, L.R., 1994. Dangerous Diagnostics: The Social Power of Biological Information. University of Chicago Press. 
Nelson, R.R., Winter, S.G., 1982. An Evolutionary Theory of Economic Change. Harvard University Press.

Nightingale, P., Martin, P., 2004. The myth of the biotech revolution. Trends Biotechnol. 22, 564-569.

O’Connell, D., Hickerson, K., Pillutla, A., 2010. Organizational Visioning: An Integrative Review. Gr. Organ. Manag. 36, 103-125.

PriceWaterhouseCoopers, 2005. Personalized medicine: the emerging pharmacogenomics revolution.

Prior, L. (2001). Rationing through risk assessment in clinical genetics: all categories have wheels. Sociology of Health and Illness, 23(5), 570-593. doi:10.1111/1467-9566.00266

Rip, A., Misa, T.J., Schot, J., 1995. Managing technology in society. Pinter Publishers, London, New York.

Robinson, D.K.R., 2009. Co-evolutionary scenarios: An application to prospecting futures of the responsible development of nanotechnology. Technol. Forecast. Soc. Change 76, $1222-1239$.

Robinson, D.K.R., Propp, T., 2008. Multi-path mapping for alignment strategies in emerging science and technologies. Technol. Forecast. Soc. Change 75, 517-538.

Roelofsen, A., Broerse, J.E.W., de Cock Buning, T., Bunders, J.F.G., 2008. Exploring the future of ecological genomics: Integrating CTA with vision assessment. Technol. Forecast. Soc. Change 75, 334-355.

Selin, C., 2007. Expectations and the Emergence of Nanotechnology. Sci. Technol. Human Values 32, 196-220.

Shell, 2014. Shell New Lens Scenarios [WWW Document]. URL http://www.shell.com/global/future-energy/scenarios/new-lens-scenarios.html (accessed 12.1.14).

Society, R., 2005. Personalised medicine: hopes and realities. London.

Teece, D.J., Pisano, G., Shuen, A., 1997. Dynamic capabilities and strategic management. Strateg. Manag. J. 18, 509-533.

Tutton, R., 2011. Promising pessimism: Reading the futures to be avoided in biotech. Soc. Stud. Sci. 41, 411-429.

Van de Ven, A.H., 1992. Suggestions for studying strategy process: A research note. Strateg. Manag. J. 13, 169-188.

Van Lente, H., 2003. Role finding and positioning theory: how intermediary organizations operate in innovation systems, in: ASEAT Conference. Manchester.

Van Lente, H., Rip, A., 1998. The Rise of Membrane Technology: From Rhetorics to Social Reality. Soc. Stud. Sci. 28, 221-254.

Van Lente, H., Spitters, C., Peine, A., 2013. Comparing technological hype cycles: Towards a theory. Technol. Forecast. Soc. Change 80, 1615-1628.

Van Merkerk, R.O., van Lente, H., 2005. Tracing emerging irreversibilities in emerging technologies: The case of nanotubes. Technol. Forecast. Soc. Change 72, 1094-1111.

Van Notten, P.W.., Rotmans, J., van Asselt, M.B.., Rothman, D.S., 2003. An updated scenario typology. Futures 35, 423-443. 
Van Rijswoud, E., Stemerding, D. en S.T., 2008. Genetica, genomics en gezondheidszorg een toekomstverkenning. Nijmegen.

Wright, G., Cairns, G., Bradfield, R., 2013. Scenario methodology: New developments in theory and practice. Technol. Forecast. Soc. Change 80, 561-565. 